\title{
The Socio-economic Factors Affecting Animal Breeding in Urban Households
}

\author{
Jawad Atef Al-Dala'een ${ }^{1}$ \\ ${ }^{1}$ Assistant Prof. of Agricultural Economics, Karak University College, Balqa Applied University, Jordan \\ Correspondence: Jawad Atef Al-Dala'een, Assistant Prof. of Agricultural Economics, Karak University College, \\ Balqa Applied University, Jordan.
}

Received: November 17, 2017

Accepted: December 18, 2017

Online Published: December 25, 2017

doi:10.5430/ijba.v9n1p36

URL: https://doi.org/10.5430/ijba.v9n1p36

\begin{abstract}
The objective of this research is to investigate the socio-economic conditions of households who have animal production gardens. The questionnaire was used to collect data. The questionnaire concentrated on collecting data about animal breeding patters, the extent of these animals in these gardens. The sample was distributed on six stratified layers each layer represent a pattern of household income except the sixth layers which represents household gardens suburban areas. The results showed that households concentrate on animal breeding in their gardens. The type of animal breeding depends on the location of layers and laws, which regulate this process. In suburban areas, all kinds of animal were allowed to breed in household gardens. The production attained of animal breeding was very considerable and can be considered as part of household income.
\end{abstract}

Keywords: household gardens, animal breeding, animal production economics

\section{Introduction}

In some areas especially in developing countries, animal production practiced as one of the household activities for different purposes. Animal production as part of household activities in urban and suburban areas is considered more complicated compared to plant production. The environmental effect of animal production in society is considered one of the constrains that affect animal breeding in household gardens (Rodrigue et al., 2015). On the other hand, animal production in household gardens considered one of the economic support for families (Legesse et al. 2016).

In different countries, gardens production considered an economic activity that would lead to change the financial conditions of families (FAO, 2007). The social structure of families that breed animal production is extremely different from social structure of plant production gardens. These differences related to education and family income (Rodrigue et al., 2015). Animal production improves the nutritive conditions of families as all animal breeding is used either for consumption or sale (Fandohan et al., 2011). This indicates that household animal production considered a major solution for poverty and alleviate hunger in different developing societies (Domene and Sauri, 2007; Mazzumdar and Mazzumdar, 2011).

In some suburban areas, animal production considered as integrating activity to garden plant production. In these areas, some garden spaces planted with animal forages. This will enhance the use of free spaces inside household to support family economy (Gastom et al., 2005). In developing countries, some countries considered that introducing financial support for animal production is one of the solution for unemployment, poverty and increase food security (Burn et al., 1989; Faber et al. 2002).

\section{Methodology}

The objective of this research is to study the distribution of animal breeding as a part of household urban and suburban agricultural practices. The research will investigate the scio-economic characteristics of households that practice animal breeding as well as the purpose of production. Questionnaire was used as a tool to collect data. The questionnaire introduced questions about the area of household gardens, family characteristics, production of animal breeding activities and the uses of production. The animal production parts are considered part of more comprehensive questionnaire that covers also plant production, environmental aspects and gardens management information.

The survey included households in urban and suburban areas in large cities specially Amman; the capital of Jordan. 
The study population was divided into different strata as follow:

Layers classification

Layers 1: represents the people with low income

Layer 2: represents people with low to moderate income

Layer 3: represents people from moderate to high income

Layer 4: represents the people with high income

\section{Layer 5: represents Wadi Al Ssir Area}

Layer 6: represents Amman suburbs

Simple random sample selected in harmony with sample size from each strata.

\section{Results}

The social structure of society reflected on the type of animal breed in household gardens. Also, the space of household gardens affected the type of animals breed in household gardens. The highest number of gardens was specialized in breeding chicken followed by pigeon. These two types of birds need less space for breeding and their production will improve families lives (Figure 1). The third type of animals that found in household gardens is the goats, which is considered one of the animals that is breed in rural areas. The least type of animals was rabbits. The other types of animal including ducks, geese, bees horses did not exist in household gardens because either these animals are not widely breed in Jordan or because it need high space for breeding.

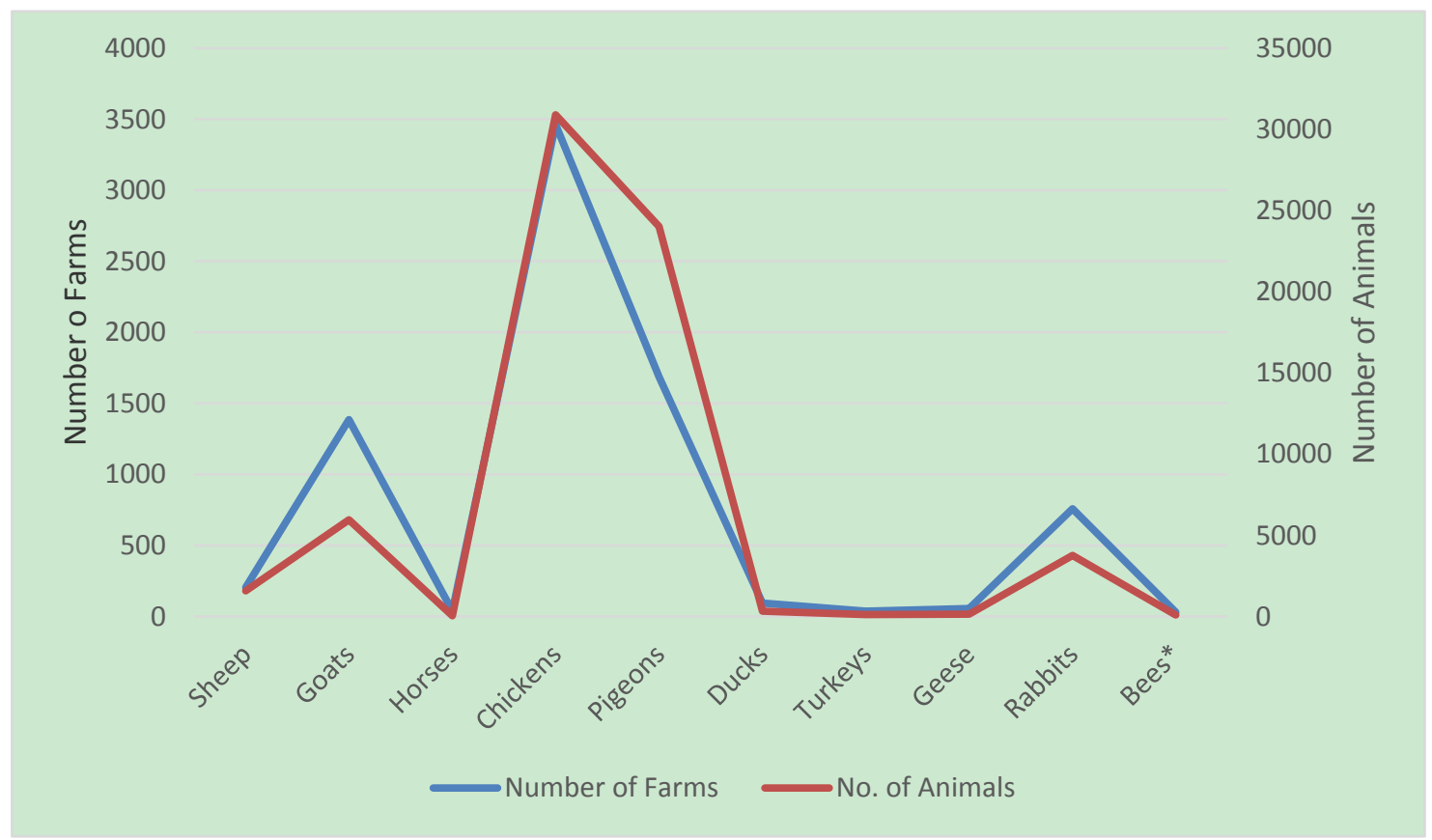

Figure 1. The type of animals breed in household urban gardens

The number of gardens for chicken, goats, pigeons, rabbits and sheep was higher in the six layer. The higher distribution of these animals in the sixth layer is that these gardens found in suburban areas, which makes the breeding of animal more simple without any environmental or social negative effects (Figure 2). Small number of gardens with chicken and pigeons breeding were found in layers from 1 to 5 , while the least number of farms was recorded for the rare breeding animals including turkey, geese, bees, horses and ducks. 


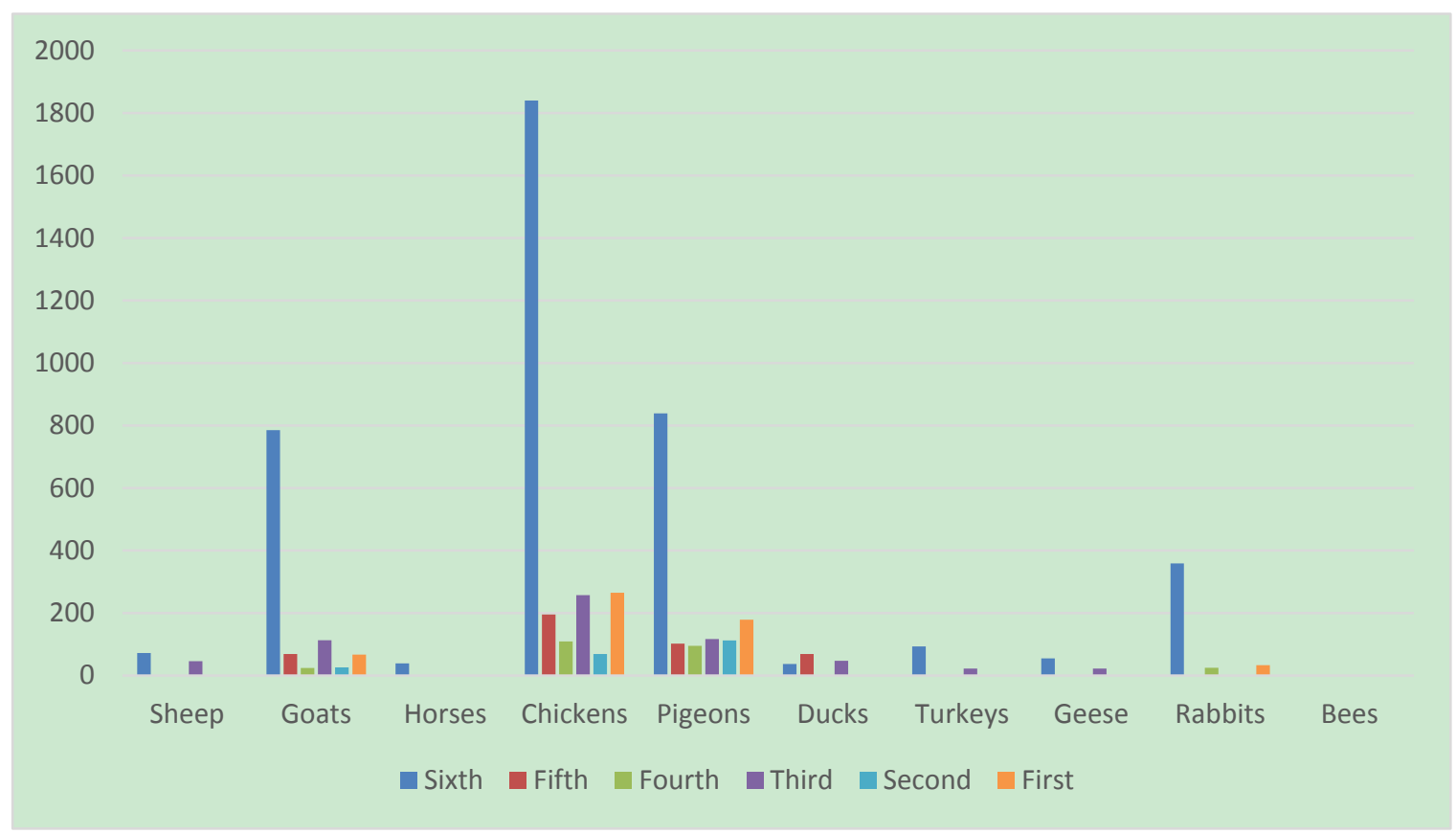

Figure 2. The distribution of number gardens according to different layers

The highest number of animals was recorded for chicken, followed pigeons, rabbits, goats and the least was recorded for sheep in the sixth layer (Figure 3). The number of animal recorded in other layers was sharply less, indicating that animal breeding was not major in the first layer to fifth layer due to either the low space or the location of layers among residential areas.

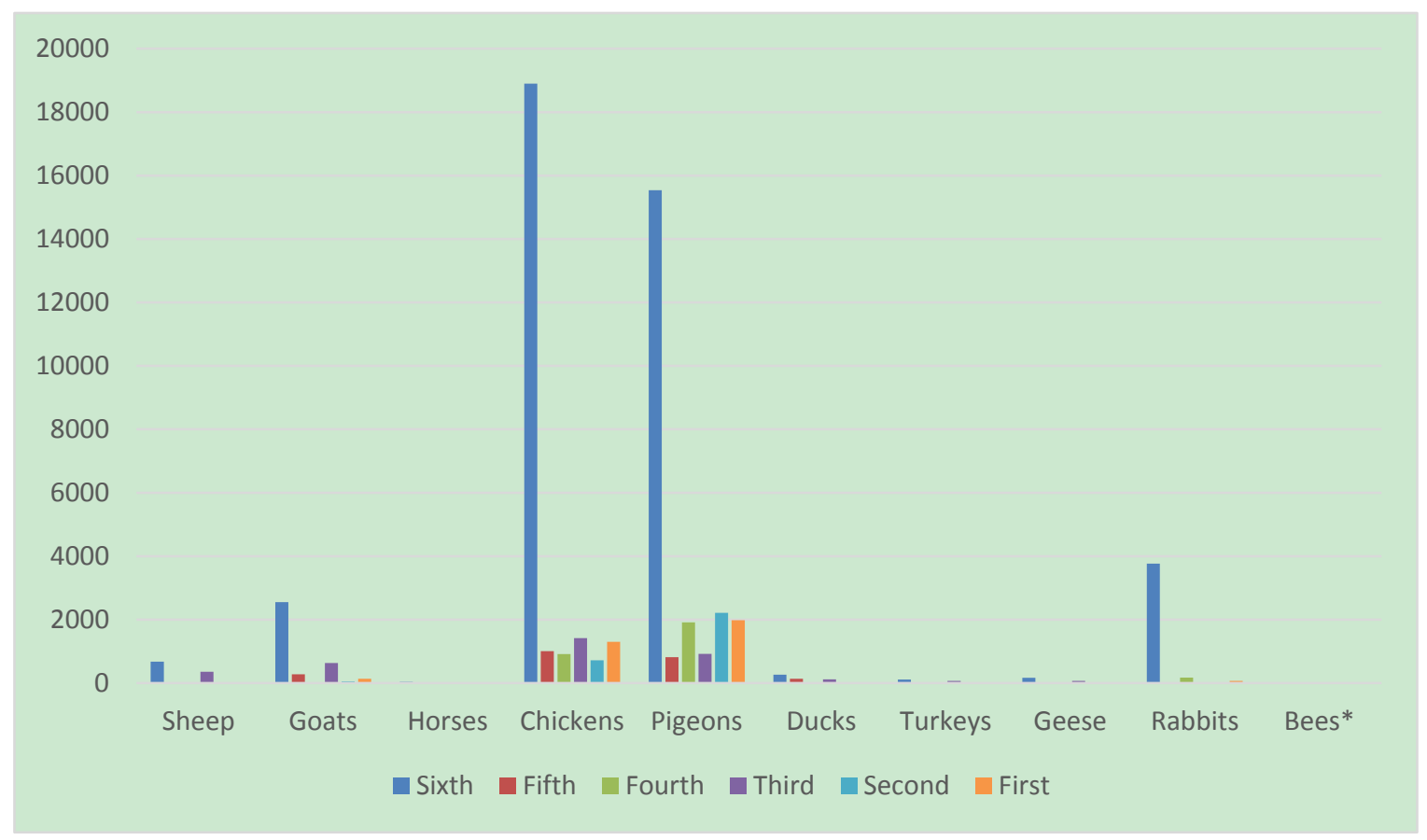

Figure 3. Number of animals per layer

The highest number of animal was recorded in large garden areas (>200 square meters). This pattern was recorded 
for chicken, pigeons, and rabbits. The second highest animal distribution was for the area 100-200 square meters for chicken, pigeons, goats, sheep, and rabbits as the area makes it possible for breeding of such animals. For pigeons, the number was high in gardens with less than 20 square meters because pigeons in most cases is breed inside gardens using very small area with the concentration on vertical space (Figure 4).

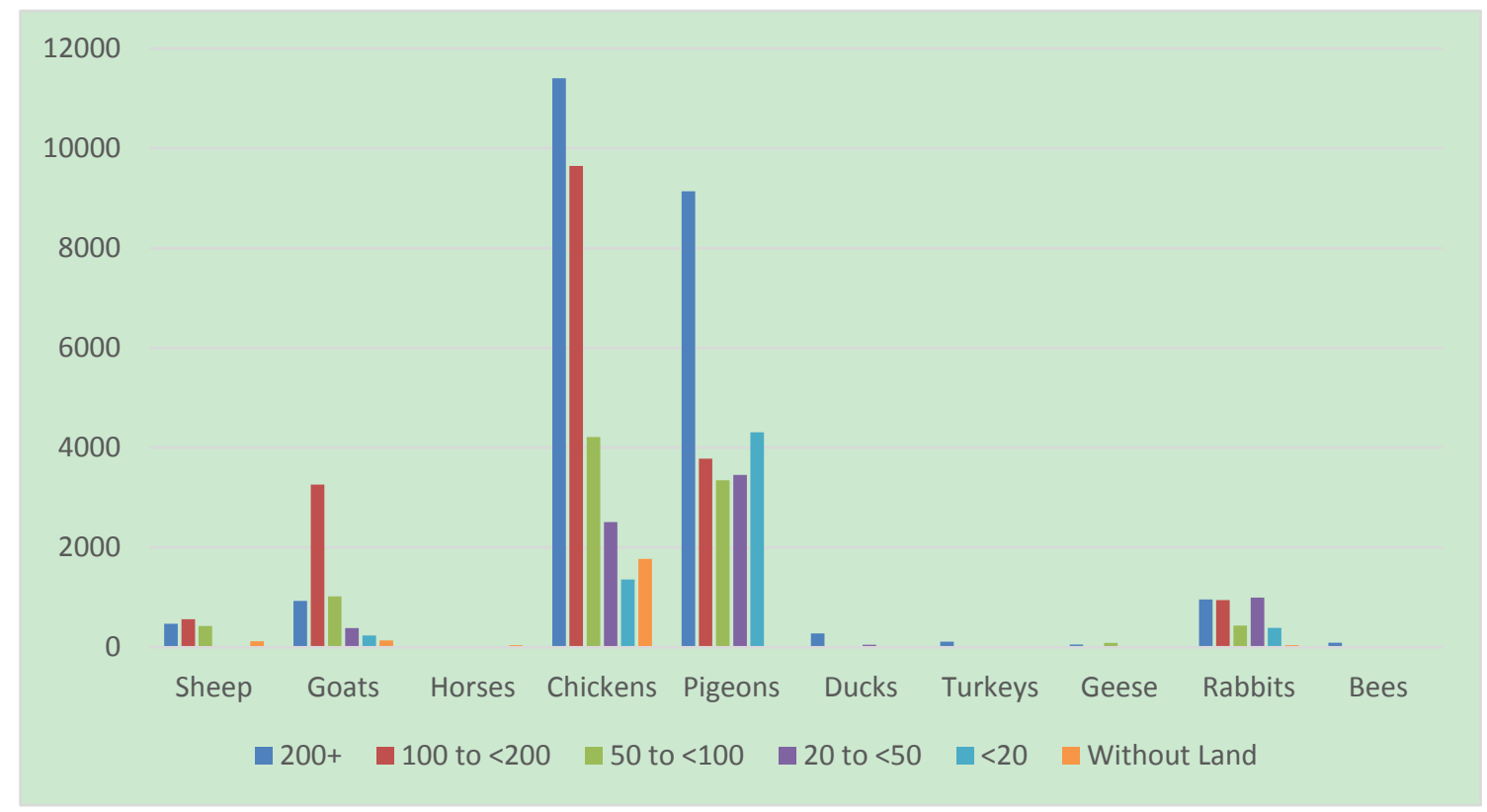

Figure 4. Number of animals by area category of garden

The results showed that the highest production was recorded for eggs followed by sheep and goats milk (Figure 5). The highest return was recorded for sheep and goats new born as its singular price is considered the highest compared to other productions followed by the returns of egg production. The return of animal household production can be considered as a good income for family.

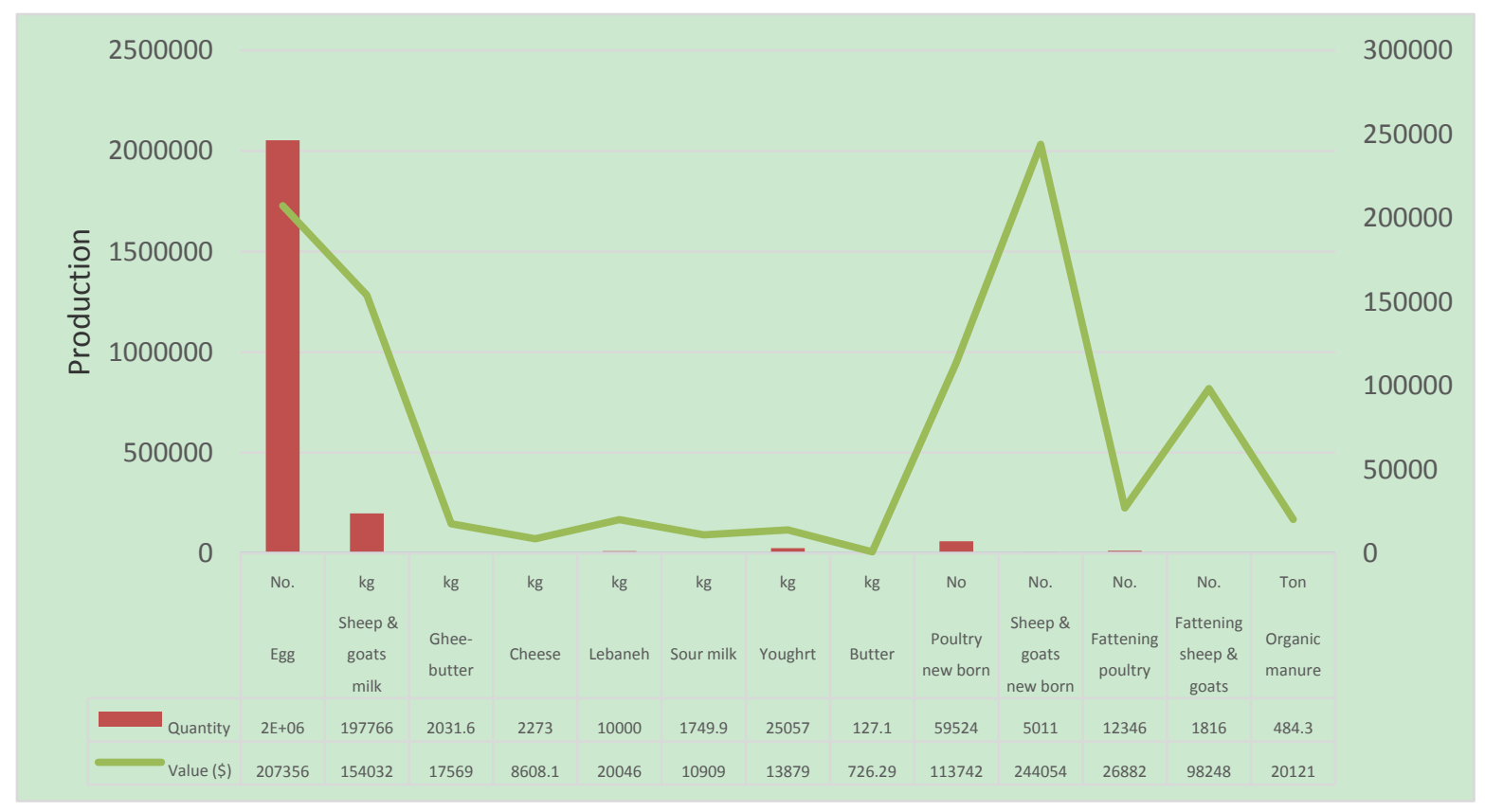

Figure 5. Animal production and value 
As mentioned before, animal production was affected by the location. The highest animal production was found in layers 6, which is a layer located in suburban places. This is considered logic as the regulations forbidden animal raising in residential areas due to environmental and social considerations. The sixth layer had the highest animal production for all types of production. The highest production in layers sixth was for eggs followed by fattening poultry then the poultry new born and the last was for sheep and goats. The quantities of production are considerable economically for households (Figure 6).

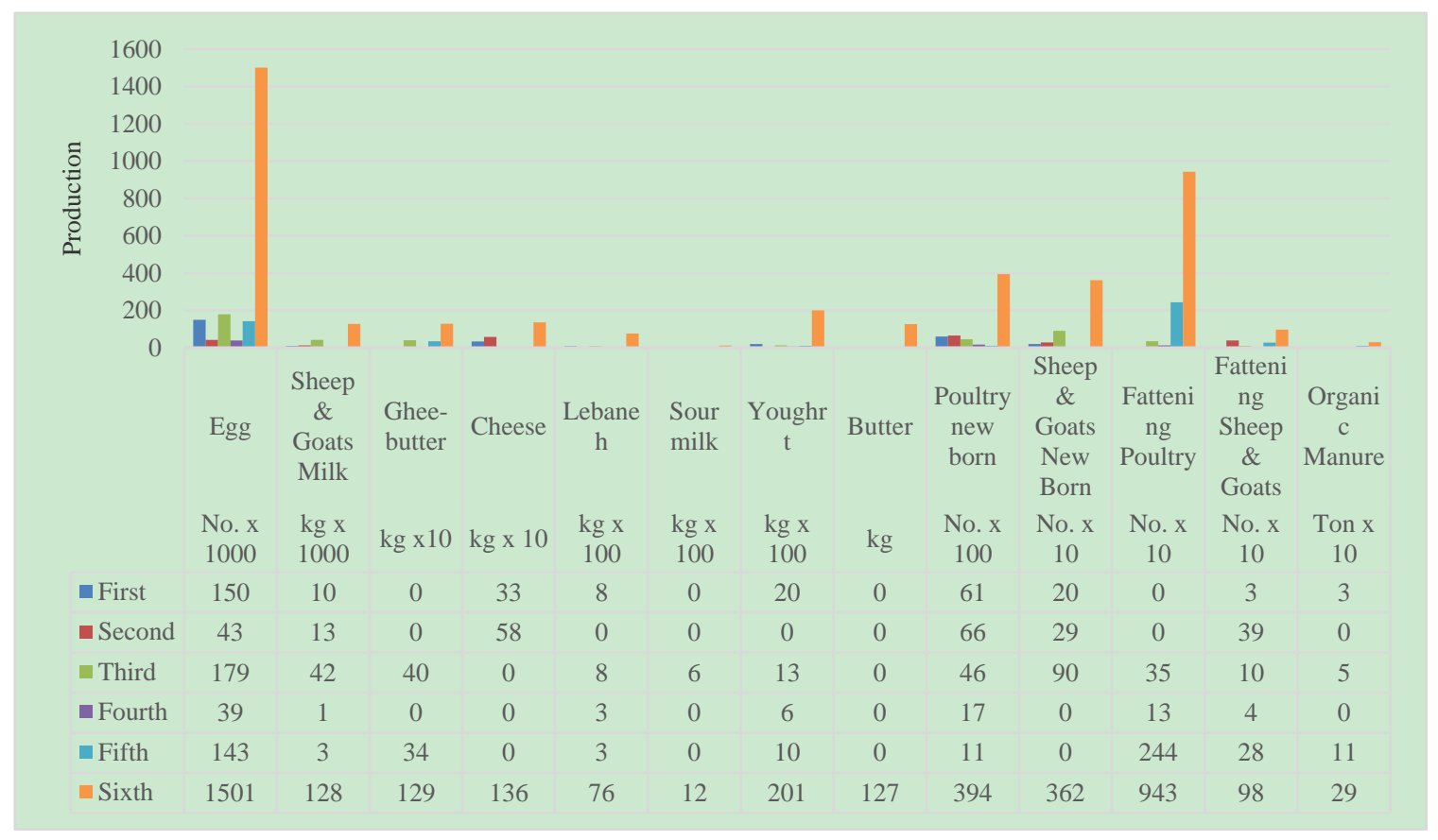

Figure 6. Animal production according to layer

Concerning the returns of animal production, the highest amounts of returns was recorded for sheep and goats new born of about $173,754 \$$ then followed by egg production with returns reached $148,898 \$$. The third returns was recorded for sheep and goats milk of about 84,763\$ (Figure 7). The returns for the layers 1 to 5 were minimal considered to layer 6 . For eggs, the returns recorded for the third layers was $20,653 \$$, while for the fifth layer the returns were $15,177 \$$ which are still considered high value for household animal production. Also for sheep and goats milk, the third and fifth layers were higher compared to layers other than the sixth one.

In some layers, there was not any animal production such as for ghee-butter which was not produced in the first, second and fourth layers. Also the butter production was existed in all layers except the sixth layer. Cheese was not produced in the third, fourth, fifth layers. This indicates that the animal production is dependent on the activities of animal breeding practiced and the type of animal breeding in each layers.

In the first layer with the least income, the highest production was recorded for eggs followed by poultry new born. These two activities indicates that in this layer, the poultry breeding is the major one. In second layer, with larger spaces and more household income, the pattern of breeding was a little bit different which affecting the type of products of this layer. In the fifth layer, most of animal types are their which reflected on the animal production items. 


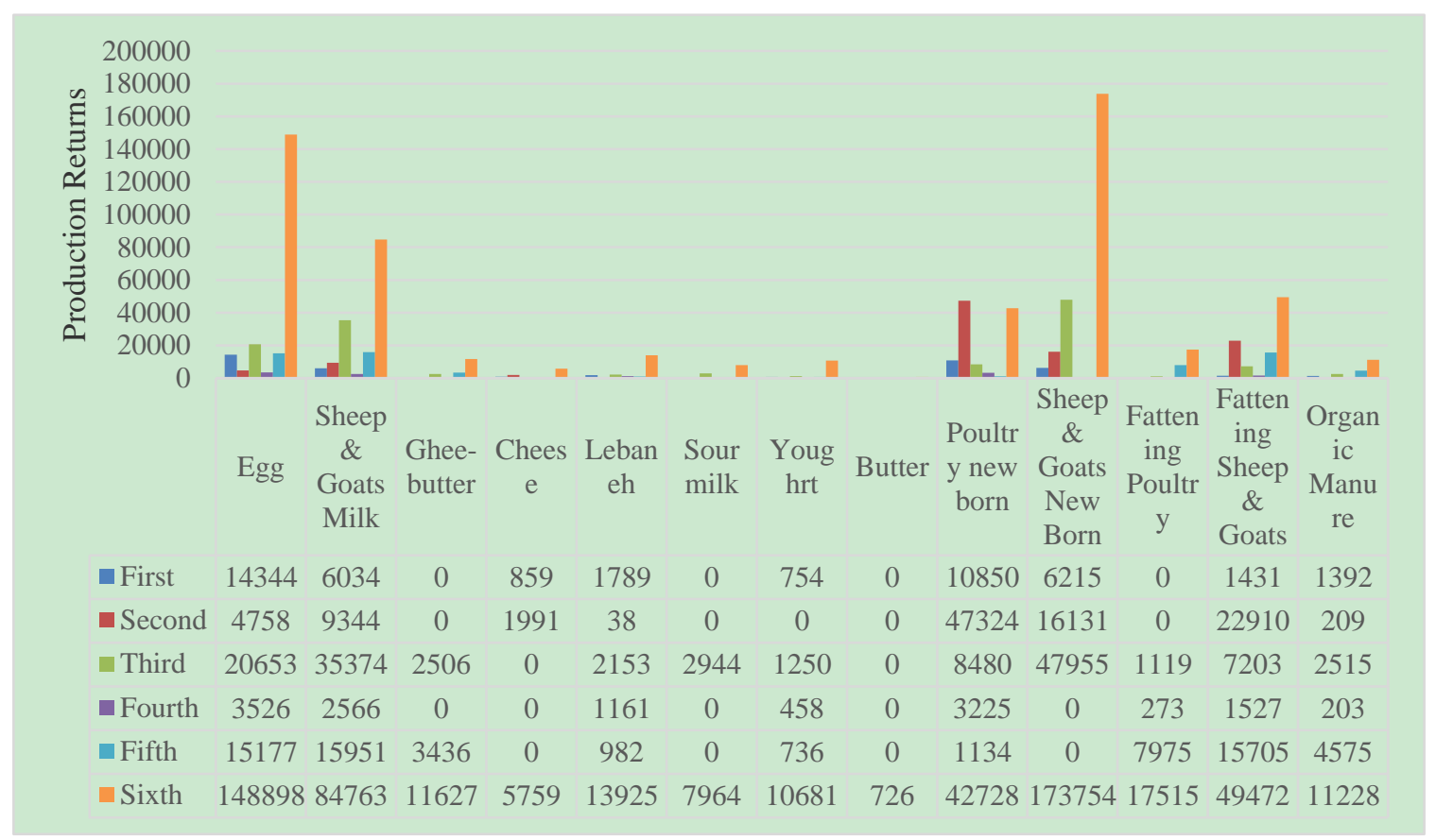

Figure 7. Returns (\$) of animal production accoding to layer

Most of animal production is used for household consumption. The highest household production was recorded for the products that considered part of household food habitts including egg, sheep and goats milk, ghee-butter, cheese, lebaneh, sour-milk, youghurt, butter, poultry new born, and fattening poultry. The results showed that household give gifts for some products sushc as eggs, sheep and goat milk, butter and organic manure. Also, selling products is used for the products that exceeds the family needs such as eggs, sheep and goat mild,ghee-butter, cheese, lebaneh, and youghurt (Figure 8).

Figure 9 shows the quantities of animal production that processed isnide household to produce new items. The highest processed item is for youghurt. The third processed item was for lebanah, while the processed amounts of ghee-butter, cheese and sour-milk were lower compared to other products.

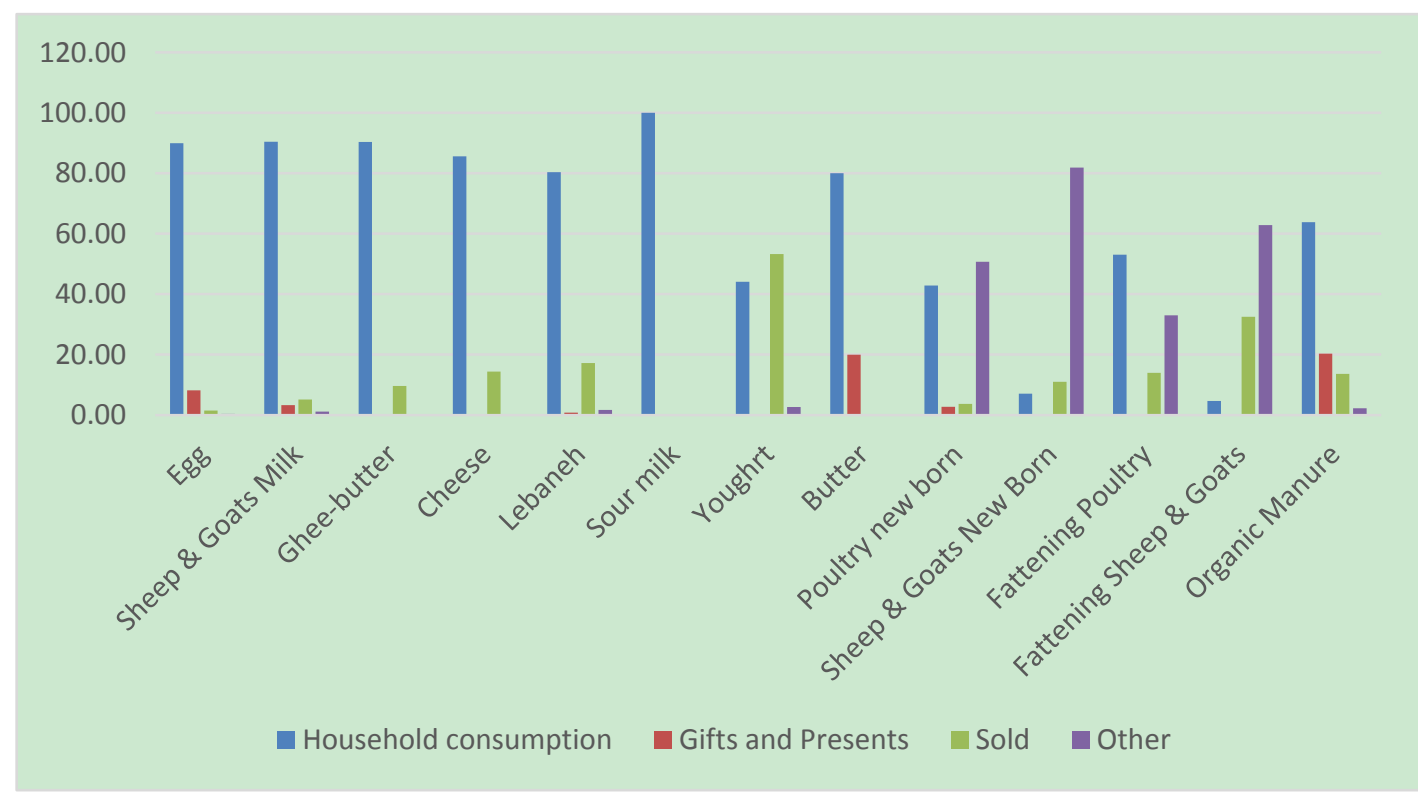

Figure 8. Animal production uses 


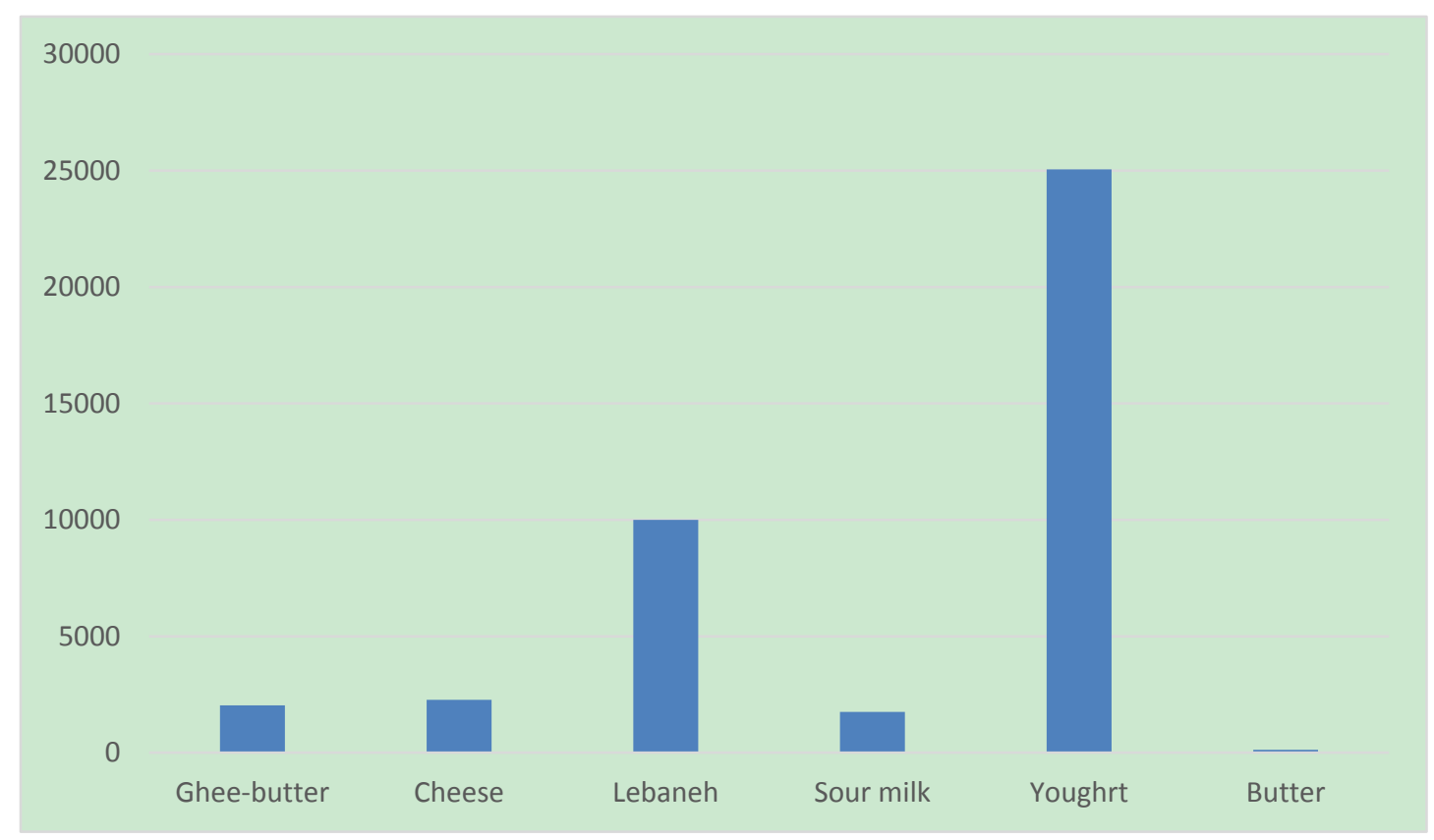

Figure 9. Animal production processed quantities $(\mathrm{kg})$

\section{Conclusion}

The objective of this paper was to investigate the socio-economic characteristics of household gardens for animal production. The questionnaire was used as a tool to collect data. The questionnaire included information about plant, animal production, environmental aspects. This paper concentrated on animal production in household gardens. The results showed that the constrains on practicing animal production in urban areas was high compared to plant production. This justifies the lack of animal production in some layers. In some layers especially the layers of low income and in gardens of low space, the concentration was on animal that does not require high space for breeding such as chicken and pigeons. In areas with more income and higher garden space, the results showed that animal breeding exceeding these two species to rabbits and sheep and goats. Through this research, the households considered that animal production as a major economic activity that supports the household income. Throughout this research, the animal production was converted to money, but for household animal production was used to save their expenses in different life aspects.

The results showed that the household practices is looking for sustainability. In other words, the families uses the new born animals to sustain their animal production. They consider the new born as the replacement of the old cattle that they use for household consumption. In some aspects of household animal breeding, they utilize the organic manure produced to support the plant production in their gardens.

Some household rely on selling the animal products to save money for their households for other expenses. The households concentrated on using raw animal products and process it to produce new products that can be sold in neighborhood or to the local markets. The returns in some cases can be considerable and may considered as a separate income for households. This enrich the idea of supporting the household production as a tool to alleviate poverty and improve household nutritive status.

\section{References}

Brun, T., Reynaud, J., \& Chevassus-Agnes, S. (1989). Food and nutritional impact of one home garden project in Senegal. Ecol Food Nutr., 23, 91-108. https://doi.org/10.1080/03670244.1989.9991092

Domene, E., \& Saurí, D. (2007). Urbanization and class-produced natures: Vegetable gardens in the Barcelona Metropolitan Region. Geoforum, 38, 287-298. https://doi.org/10.1016/j.geoforum.2006.03.004

Faber, M., Venter, S.L., \& Benade, A. (2002). Increased vitamin A intake in children aged 2-5 years through targeted home-gardens in a rural South African community. Public Health Nutr., 5, 11-16. https://doi.org/10.1079/PHN2001239 
Fandohan, B., Assogbadjo, A.E., Glèlè Kakaï, R.L., \& Sinsin, B. (2011). Effectiveness of a protected areas network in the conservation of Tamarindus indica (Leguminosea-Caesalpinioideae) in Benin. Afr J Ecol., 49, 40-50. https://doi.org/10.1111/j.1365-2028.2010.01228.x

FAO. (2007). Profitability and sustainability of urban and per-urban agriculture.

Gastom, K., Warren, P.; Thompson, K., \& Smith, R. (2004). Urban domestic gardens (IV): the extent of the resource and its associated features. Biodiversity and Conversation, 4, 3327-3349. https://doi.org/10.1007/s10531-004-9513-9

Legesse, A., Tesfay, G., \& Abay, F. (2016). The impact of urban home gardening on household socio-economy. Arts and Design Studies, 39, 21.

Mazumdar, S., \& Mazumdar, S. (2012). Immigrant home gardens: Places of religion, culture, ecology, and family. Landsc Urban Plan, 105, 258-265. https://doi.org/10.1016/j.landurbplan.2011.12.020

Rodrigue Castro Gbedomon, Adandé Belarmain Fandohan, Valère Kolawolé Salako, Alix Franck Rodrigue Idohou, Romain Glèlè Kakaï, \& Achille Ephrem Assogbadjo. (2015). Factors affecting home gardens ownership, diversity and structure: a case study from Benin. J. Ethnobiol Ethnomed, 11 , 56. https://doi.org/10.1186/s13002-015-0041-3 